\section{European Restart a Heart Day}

\author{
Andrew S Lockey
}

October 16th is European Restart a Heart Day (http://www.restartaheart.eu). This initiative, spearheaded by the European Resuscitation Council (ERC), is aimed at increasing survival rates from out-ofhospital cardiorespiratory arrest (OHCA). It was instigated in 2013 following a successful campaign by the ERC to pass a written declaration in the European Parliament, which called upon member states to improve awareness and provide cardiopulmonary resuscitation (CPR) education to the public as well as healthcare professionals. The 2010 ERC Guidelines had already endorsed the recommendation that all citizens should be taught CPR. ${ }^{1}$

Every year, approximately 350000 Europeans suffer OHCA. ${ }^{2}$ In the UK alone, the figure is estimated to be $60000 .^{3}$ Average survival rates are, at best, $12 \%$ overall with higher rates (23\%) seen in the subgroup of those who are fortunate to arrest in a 'shockable' rhythm (ventricular fibrillation or tachycardia). ${ }^{4}$ Factors that have been proven to improve survival include rapid access to defibrillation and swift onset of CPR in the meantime. For every minute that passes without CPR, survival decreases by $10 \%$. With bystander CPR, this rate drops to $2-3 \%$ per minute thus buying extra time for a defibrillator to arrive and be used successfully. ${ }^{1}$ As Deakin and Gray $^{5}$ have shown however, the presence of a nearby automated external defibrillator (AED) does not guarantee its use. We therefore need to increase awareness in the use of public access AEDs as well as train our population to perform CPR when needed.

The theme of last year's Restart a Heart Day was 'Children Save Lives'. Events were held throughout Europe to increase awareness of the problem. In the UK, the Resuscitation Council (UK) distributed a free copy of the award winning Lifesaver programme (http://www.life-saver.org.uk) to every secondary school. This interactive game, which is free to download to smart phones and tablets, immerses users into three scenarios allowing them to make real-time decisions with realistic consequences. In the process, they learn about $\mathrm{CPR}$, choking management and AED use.

Correspondence to Dr Andrew S Lockey, Emergency Department, Calderdale Royal Hospital,

Halifax HX3 3HW, UK; Andrew.lockey@cht.nhs.uk
There is compelling evidence that areas that invest in teaching children the skills of CPR have better survival rates. This is predominantly due to the associated higher rates of bystander CPR rates as more of the population is trained. In Copenhagen, ${ }^{6}$ where they have been training school children since 2005 , bystander CPR rates are $44.9 \%$ with a survival rate for shockable rhythms of $32 \%$. In Stavanger, ${ }^{7}$ where training was first instigated in 1985, bystander CPR rates are $73 \%$ and survival from shockable arrests is $48 \%$. Similarly in Seattle, ${ }^{8}$ the bystander rates are $61 \%$ and survival from shockable arrests is $49 \%$. Compare this with the dismal rates in countries like the UK (bystander CPR rate 30\% and survival in shockable rhythms of 23\%) where no such mandate to teach children exists. ${ }^{3}$

The Resuscitation Council (UK) and British Heart Foundation have been actively campaigning to make CPR training a mandatory element of the national schools' curriculum with little success. Primary school children could learn the concepts of first aid including the recognition of the unwell person, the recovery position, and calling for help. Secondary school children are physically able to deliver CPR and learn about AEDs. ${ }^{9}$ In some areas of the country, enthusiastic campaigners have ensured that their local schools teach these skills although the effort to sustain this training is made more difficult for the lack of any mandatory requirement.

In this issue, a review by $\mathrm{He}$, Wynn and Kendrick $^{10}$ has concluded that there is evidence to support provision of first-aid training to children. While their review highlights a paucity in evidence, there are indications that training leads to increases in knowledge, skills and confidence in undertaking first aid. The papers reviewed demonstrated a high risk of bias and the age ranges studied were variable. They encountered the challenges that face all studies looking at the impact of educational interventions in first aid and life support. The outcomes that are easiest to measure (eg, immediate impact upon knowledge and skills) are of limited interest compared with those that are more difficult to measure and that do matter (eg, impact upon patient care and survival). These latter outcomes would require massive studies to show a positive correlation and as such do not tend to be done. Until they are, we are limited to studies that show immediate benefits in terms of knowledge and skills and increased enthusiasm. It is important however that this is not undervalued and the evidence from many years of training school children in places like Copenhagen, Stavanger and Seattle should give us assurance that there is a potential correlation with improved patient outcomes.

The importance of such training is further evidenced by the tragic case highlighted in this issue by Xiuli et $a l^{11}$; however the authors describe a more disturbing reason for lack of bystander help. The details of what happened in Shenzhen are harrowing and it is appropriate that a widespread debate was triggered as a result. It is of huge concern that innocent rescuers may be seen as perpetrators and prosecuted in China. This reaction has to be challenged and halted through top-down legislation to protect 'good Samaritans', such as the one recently announced in England and Wales ${ }^{12}$, otherwise many more innocent lives will be lost.

The theme for this year's Restart a Heart Day is 'Loved Ones Save Lives'. This reflects the fact that the vast majority of OHCAs occur in the home, where family members are the only witnesses and therefore the only ones with the chance to save their loved ones.

In Canada, Vaillencourt et $a l^{13}$ have estimated that $85 \%$ of OHCAs occur in the home, and that half are witnessed by a family member or friend (usually over the age of 55 years). This prompted them to look at the behaviour traits that influence willingness to perform CPR. Their sample population included 24 volunteers over the age of 55 years. Through a series of semistructured qualitative interviews, they concluded that there is an understanding of the importance of CPR training with a desire to help loved ones should the need arise. This was balanced however with a fear of 'doing wrong', worries about physical limitations that may impair ability to deliver CPR, and an ambivalence to act in group situations. There are important messages to be learnt in terms of strategies to engage and enthuse this cohort in learning CPR skills. The authors clearly acknowledge the main limitations of this paper-namely that the subjects interviewed were all volunteers and the majority had prior training in CPR. It would have been interesting to gain a range of opinions from those with no prior training or interest in the topic.

The evidence from Copenhagen, Stavanger and Seattle show that survival 
rates of two to three times the current levels are achievable. This would equate to up to 100000 additional lives saved per year across Europe. Investing resources into teaching CPR and also awareness of AEDs is needed, particularly in situations where OHCA is likely to be witnessed. Targeting school children with education ensures that they have lifelong skill sets that convert them into life-savers. It is the easiest way to train the broadest slice of the population. Additional targeting of high-risk groups will further improve survival statistics.

There is significant variability in practice across Europe in terms of first aid and CPR training with very few countries that reliably deliver this training in a standardised format. ${ }^{14}$ Until there is a central mandate in every European country to deliver this education, the European Restart a Heart Day will continue. It is our duty to encourage and expand the pockets of enthusiastic activity that currently exist and inspire other areas to follow their example.

So, what will you do on 16 October 16 2014 ? First of all, ensure that your own training in basic life support skills is up to date. Next, ensure that your loved ones are also trained-you may personally benefit from this investment in the future. Organise an event on the day to raise awareness about this problem. The Resuscitation Council (UK) will endeavour to help promote any UK initiatives and can be contacted on restartaheart@resus.org. uk. Finally, contact your local school(s) to see if they are delivering CPR training. If they are, encourage them to continue. If not, and if it is within your gift, help support and encourage them to do so.

Competing interests AL is Honorary Secretary of Resuscitation Council (UK) and Vice Chairman of the Education Working Group of the European Resuscitation Council.

Provenance and peer review Commissioned; internally peer reviewed.

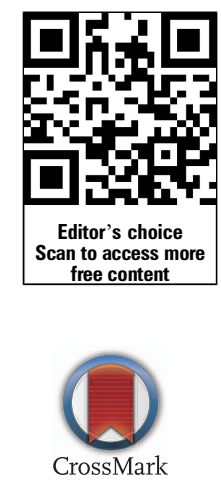

To cite Lockey AS. Emerg Med J 2014;31:696-697.

Received 20 June 2014

Accepted 23 June 2014

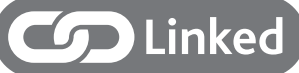

- http://dx.doi.org/10.1136/emermed-2012-202192

http://dx.doi.org/10.1136/emermed-2013-202389

- http://dx.doi.org/10.1136/emermed-2014-204012

Emerg Med J 2014;31:696-697.

doi:10.1136/emermed-2014-204111

\section{REFERENCES}

1 Soar J, Mancini ME, Bhanji F, et al. Part 12: education, implementation, and teams: 2010 international consensus on cardiopulmonary resuscitation and emergency cardiovascular care science with treatment recommendations. Resuscitation 2010;81:e288-332.

2 Berdowski J, Berg RA, Tijssen JG, et al. Global incidences of out-of-hospital cardiac arrest and survival rates: systematic review of 67 prospective studies. Resuscitation 2010;81:1479-87.

3 Ambulance service association, the joint royal college ambulance liaison committee. National

Out-of-hospital Cardiac Arrest (OHCA) project. 2006.

4 Perkins GD, Cooke MW. Variability in cardiac arrest survival: the NHS Ambulance Service Quality Indicators. Emerg Med J 2012;29:3-5.

5 Deakin CD, Shewry E, Gray HH. Public access defibrillation remains out of reach for most victims of out-of-hospital sudden cardiac arrest. Heart 2014;100:619-23.

6 Wissenberg M, Lippert FK, Folke F, et al. Association of national initiatives to improve cardiac arrest management with rates of bystander intervention and patient survival after out-of-hospital cardiac arrest. JAMA 2013:310:1377-84.

7 Lindner TW, Søreide E, Nilsen OB, et al. Good outcome in every fourth resuscitation attempt is achievable: An Utstein template report from the Stavanger region. Resuscitation 2011:82:1508-13.

8 Division of Emergencoy medical Services, Seattle and King County. Annual report to the King County Council; 2012. http:///kingcounty.gov/healthservices/ health/ /media/health/publichealth/documents/ems/ 2012AnnualReport.ashx

9 Colquhoun M. Learning CPR at school-everyone should do it. Resuscitation 2012:83:543-4.

10 He Z, Wynn P, Kendrick D. Non-resuscitative first-aid training for children and laypeople: a systematic review. Emerg Med J 2014;31:763-8.

11 Dan X, Liu W, NG TB. Chinese bystanders in medical emergencies: apathetic or bewildered? Emerg Med J 2014;31:698-9.

12 https://www.gov.uk/government/publications/socialaction-responsibility-and-heroism-bill-delegatedpowers-memorandum

13 Vaillancourt C, Charette M, Kasaboski A, et al. Barriers and facilitators to CPR knowledge transfer in an older population most likely to witness cardiac arrest: a theory-informed interview approach. Emerg Med J 2014;31:700-5.

14 Lockey AS, Georgiou M. Children save lives. Resuscitation 2013;84:399-400. 